\begin{abstract}
We use organisational justice theory to examine how perceptions of fairness affect the decision-making process of line managers. In-depth interviews were conducted with 3 Irish managers to explore how managers make organisational allocation decisions in cases where it is impractical to offer work-life balance accommodations to all employees. The findings suggest that firstly, managers construct the 'life' aspect of work-life balance within a heteronormative framework where the emphasis is upon caregiving and most usually parenting. Secondly, managers actively use their decisionmaking powers around both formal and informal work-life balance supports to minimize injustice within their departments. By bringing together ideas about organisational justice and managerial decision-making we indicate how managers determine fairness through a decision-making process narrowed by embedded genderrole beliefs. Implications for future research and practice are discussed.
\end{abstract}

Keywords —organisational justice, gender- role beliefs, managerial decisionmaking, work-life balance, family-friendly policies, managerial discretion. 


\section{The subjectivity of fairness: Managerial discretion and work-life balance}

\section{Introduction}

Organisational work-life balance arrangements are often described as a way for workers to maintain a healthy balance between their life in paid work and their personal life outside. Organisations implement such programmes in the hope of increasing employee commitment and retention (Allen et al. 2003) along with a desire for a more balanced and productive staff (Russell et al. 2009) and the business case for such interventions is now well-documented (Theodorakapoulos and Budhwar, 201 5). However, while many organisations have (re)constructed workplace arrangements in universally available and gender-neutral terms, research suggests that there remains a disconnect between organisational discourse and practice (Smithson and Stokoe 200 5). It seems that in spite of claims of universality, allocation tends to favour the care-giving needs of working mothers. This gendered distribution has perpetuated a perception that these arrangements are, in reality, family-friendly policies.

Employees who are unable to access these programmes - particularly employees without children — argue these policies create inequality in the workplace (e.g.: Teasdale, 2013). Accordingly, employees resent the 'extras' perceived to be available only to employees with families. This can lead to a sense of injustice, a backlash against 'family-friendly' policies (Young 1999) or counter-productive work behaviours (Beauregard, 2014). Research examining reactions to perceived inequality highlights the risk of employee anger, indignation and resentment that can emerge when employees feel under-rewarded (Homans 1974; Hegtvedt and Killian 1999; Beauregard, 2014). 
A number of studies have examined perceptions of injustice towards work-life balance programmes (Bond et al. 1998; Young 1999; Hegtvedt et al. 2002; Swanberg et al. 200 5; Beauregard, 2014) but these have focused exclusively on individual employees. Here instead, we contribute by investigating managerial perceptions of justice in the context of work-life balance. Scholars acknowledge that managers play an important role in the operation of work-life balance programmes (Warren and Johnson 199 5; Casper et al. 2004; McDonald et al. 2007) and are increasingly expected to do so (Todd and Binns, 2013). Although managerial decision-making is clearly crucial, managerial conceptions of fairness within the decision-making process remain under-explored.

In extending the focus to managerial decision-making, we uncover deeply embedded heteronormative understandings of work-life balance held by the managers and illuminate how managerial perspectives of gender-roles temper the decision process around fairness in worklife balance allocation even when they may not appear to be relevant. Extending the link between gender-role beliefs, organizational justice, and work-life balance, our qualitative approach allows us to illustrate how the 'human' elements in this process are often more influential than the formal policies in place. When considering the implications, we argue that the identification of such phenomena requires a shift in our approach to work-life balance research to allow researchers a greater chance of understanding the complexities surrounding these issues in their pursuit of stronger policy and organisational recommendations.

The paper is structured in the following way. We begin by outlining the literature on work-life balance and position this study within the literature on managerial discretion. Second, we examine the literature that underpins the conceptual contribution of the paper organisational justice. Third, we present the gender-role theoretical framework used in this study followed by the research methodology. Fourth, we present the findings, and finally, we discuss those findings and their implications. 


\section{Work-life balance and managerial discretion}

Since the 1980's there has been considerable interest in the area of work-life balance by scholars in a range of different fields. Gregory and Milner (2009:1) highlight how the term has now "gained widespread use in English language research and policy arenas, enabling a wider understanding of non-work concerns to be encompassed in employment research". A plethora of research has been conducted using the term with a variety of foci. Examples include the impact of work-life balance upon psychological well-being (e.g. Greenhaus and Beutell, 198 5); organizational benefits such as increased productivity and staff retention (De Cieri, Holmes, Abbott and Pettit, 2007); experiences of dual-career couples; conflict between work and family (e.g. Grzywacz and Marks, 2000); organisational change policies for worklife initiatives (e.g. Kossek et al. 2010); international patterns of work-life balance (Crompton and Lyonnete, 2006) and gender differences (e.g. Emslie and Hunt, 2009).

Within the literature it is evident that the role of managers within work-life balance is important and those advocating a business case for managing diversity more generally note the importance of their support (Theodorakapoulos and Budhwar, 201 5). As Den Dulk et al. (2011:323) highlight, "Managers support for work-life policies is crucial for shaping employee's capabilities to use them". For example, Thompson et al. (1999) concluded that managerial support was the most critical variable in an employee's decision to use supports while Allen (2001) found a strong association between managerial support and familysupportive workplace cultures. Studies reveal that employees whose line managers are more supportive of their need to balance work and life tend to be more satisfied with their own jobs, experience less work-family conflict and report lower turnover intentions (Frone et al. 1992; Frye and Breaugh 2004; Lapierre et al. 2008; McCarthy et al. 2010). 
Several studies (e.g. McGuire et al. 2006; den Dulk and de Ruijter 2008) have focused on managers' personal perspectives in relation to work-life balance supports. For example, in one study den Dulk and Ruijter (2008) focused on questionnaire responses of 46 managers to argue that personal perspectives vary largely to the degree that the managers understand the context of the request and the merits of the requestor. In a US sample, Casper et al. (2004) analysed almost 2,000 surveys to conclude that supervisor attitudes predicted decision-making when managers felt that the support would contribute to departmental performance. An important issue to consider here is the culture of the organisation. Reeve et al. (2012) investigated a range of different factors that affected managers decisions to allow employees to access work life balance arrangements in the retail and public service sector in Australia. In both sectors managers reported that workplace culture was important in determining how comfortable they were to grant access. However, business needs and operational imperatives were also important. Furthermore, Den Dulk et al. (2008:321) in a study of managerial discourses of work-life balance in three countries: Slovenia, Netherlands and the UK, concluded that in all three cases, disruption and dependency considerations were discussed to justify negative and positive responses to requests to use work-life balance policies. These studies indicate the complexities managers face when making such decisions.

\section{Perspectives of Justice}

As stated earlier, research has previously considered the impact that perceptions of justice and injustice around work-life balance policies can have on employees (Bond et al. 1998; Grandey and Cordeiron, 2002; Young 1999; Swanberg et al. 200 5, Beauregard, 2014). Grover (1991) suggests that organisational justice theory provides a useful framework for categorising fairness principles involved in work-life balance practices. Organisational justice can be categorised into four main types - distributive, procedural, interactional and informational (Jespen and Rodwell 2010). Theorists have favoured distributive justice, which refers to "the fairness of outcomes received in a given transaction" (Byrne and Cropanzano 
2001:4) for examining employees' perspectives on work-life balance arrangements.

Particularly in situations where policies do not apply to all employees (such as flexi-time or home-working), managers must decide who may access them based on their own perspective of fairness (Appelbaum and Golden 2002; Swanberg et al. 200 5). Within the domain of distributive justice there are three principles of fairness: equality (Adams 196 5), equity (Deutsch 197 5) and need (Schwinger 1986). These principles have been applied to understanding employee's reactions to decision-making and allocation of programmes such as home-working.

The equity principle is based on the assumption that rewards and resources should be allocated based on merit. In essence, equity theory implies that the distribution of work-life balance arrangements should be in direct proportion to employees' contributions to the organisation. Conversely, the equality principle holds that everyone should receive the same allocations regardless of performance or other contingencies. Specifically, Grandey (2001) suggests that according to the equality principle, "work/family policies can be considered fair when the policies are available to everyone" (:1 55). The equality principle can be applied to arrangements in two ways: either everyone gets the same benefit or everyone gets no benefit at all (Young, 1999). Finally, the need principle calls for the allocation of rewards and resources on the basis of individual circumstances. This principle suggests that those in the most need of a resource should receive it, regardless of input or output (Schwinger 1986). In this case, allocations are considered fair when given to employees with the greatest need. For the most part, these respective principles operate on a tacit level. In other words, people are typically unaware that their perceptions affect their basic assumptions of fairness and are equally unaware that their perceptions may not be shared by others.

Despite its relevance, the use of organisational distributional justice theory in worklife balance research has been limited and concerned almost exclusively with how policies 
are perceived by employees in the context of potential backlash (Grover 1991; Young 1999; Hegtvedt et al. 2002; Swanberg et al. 200 5, Beauregard, 2014). Our interest here is the extent to which perspectives of organisational distributive justice serve to influence the interpretive processes of line managers in their decision-making processes around work-life balance policies.

\section{Gender-Role Beliefs}

Given that managers will be making decisions in gendered organisational contexts (Green and Cassell, 1996), managerial beliefs about gender roles also come into play. It has been argued that differences in gender-role beliefs create differences in worldviews (Greenstein 1996 a\&b; Kroska 1997; Nomaguchi et al. 200 5) and therefore this 'gender-role lens' affects the ways that policies are created and viewed (Blair and Johnson 1992). Relatively few studies have specifically focused on gender-role views and work-life balance (Parasuraman and Greenhaus 2002) and those that have concentrate either exclusively on women (e.g. Bernas and Major 2000), or on the gender equality of such practices (e.g. Warren 2004; Lewis and Campbell 2007 \& 2008). Feminist literature defines gender-roles in terms of one's socialised sex based on what it means to be a man or a woman in a specific culture and time rather than inherent biological differences (West and Zimmerman 1989).

Discourses around gender-roles often describe perspectives on a scale from 'traditional,' where men are seen as primary workers and women as carers, to 'egalitarian' where men and women are seen as equal. Furthermore, a link between gender-role beliefs and perceptions of (in)equality has been made in research that examines the division of household labour. Despite a pervasive imbalance in the division of housework few women report an injustice (Braun et al. 2008). This appears to contradict Adam's (196 5) equity formulation where the extra work that women are performing in the division of household labour ought to generate feelings of inequality. However, in relation to household labour outcomes, feelings of (in)equality are subjective and linked to individual gender-role beliefs (Blair and Johnson 
1992; Greenstein 1996a; Crompton et al. 200 5; Braun et al. 2008; Ruppanner 2008). For example, women who hold more traditional views of gender-roles are less likely to report injustice in doing a larger share of household labour as their views of gender mitigate or legitimise this inequality (Braun et al. 2008; Ruppanner 2008). Howard and Hollander (1997) argue that this is an illustration of a 'gender lens' where personal views filter interpretations. Accordingly, it has been argued that gender-role beliefs determine how we see the world and, in this case, understand work-life balance arrangements (Greenstein 1996a\&b; Kroska 1997; Nomaguchi et al. 200 5). In support of this theory, Glover (1991) linked the belief that maternity leave is unfair with individuals holding traditional gender-role beliefs. In contrast, he found that those with 'egalitarian' gender beliefs may view the support as not 'extra' but simply a part of what is necessary for women's participation in the workplace. This finding was also supported by Hegtvedt, et al. (2002:389) who suggested that no perception of inequality is created when such policies are seen as necessary rather than 'extra'.

Yet the findings around gender-role beliefs in the work-life balance field have been mixed. In Hegtvedt et al's (2002) study for example, they used a one-item measure to examine gender-role attitudes and were surprised to find that it had no effect on overall resentment of workplace policies. Yet gender-role beliefs do not operate on a wholly conscious level and Berk (198 5:207) noted that they operate "without much notice being taken". Moreover, gender-role identities are often fractured and incoherent with abundant contradictions between what people say and what they actually feel (Hochschild 1989). In other words, particularly in Western society, individuals are so bombarded with different gender-role ideological attitudes that they may espouse views that do not reflect their actual beliefs. In light of this, single-item measures are insufficient to capture the full spectrum of this information. 
Informed by an interpretivist approach, here we are interested in managers' interpretations and constructions of gender-roles, fairness and work-life balance policies and how those interpretations impact upon decision-making. As such our aim is to investigate managerial conceptions of fairness in relation to work-life balance policies. We now turn to the methods underpinning the research.

\section{Methodology}

Three large Irish firms participated in this study. These were selected due to their diversity in relation to work-life balance levels and initiatives whilst all being large nationwide employers. One, a private manufacturing firm with over 5,000 staff, comes from a historically male field with less than $5 \%$ of their management women (all at lower and middle levels) and a reputation for being less family-friendly; another a utility company employing over 10,000 , was also male-dominated with less than $10 \%$ of women in management (a few at senior levels) but self-described as a progressive employer in supporting work-life balance; and finally a public service organisation that included two female dominated branches each responsible for over 10,000 staff with the reputation of having readily available work-life balance arrangements linked to the permeation of women in all levels of management.

All organisations were based in Dublin with operations across Ireland - an EU member state and subject to EU Directives on statutory support including maternity and parental leave minimums. Yet unlike some other EU countries, Ireland has no mandate for supplementary organisational supports and no statutory rights for paternity leave or flexible working arrangements.

Within the organisations, the term 'work-life balance' was used in a variety of ways. It was used as a description of workplace initiatives which varied across the organisation, but were broadly split by statutory (maternity and parental leaves required by law) and non- 
statutory policies (organisational-based initiatives such as flexitime). In relation to the latter, the public manufacturing organisation was the only one in the sample which offered no formal organisationally-based programmes beyond those required by law. The utility and the public service, despite separate governance, offered additional supports which were classified into five broad groupings: flexibility policies, leave arrangements, caregiving provisions, supportive arrangements, and counselling/well-being programmes. Yet there was also a general agreement that the term 'work-life balance' had its own meaning separate from HRbased practices and could denote personal views about the relationship between work and personal life.

Within the two private companies, the sample of managers was chosen under the guidance of the organisation's Executive HR Directors with the aim of providing a representative sample of managers, as well as pinpointing senior-middle manager dyads that might exhibit extremes — high or low levels of work-life balance — and capture a few special teams to the extent that they had unusual programmes or working conditions that the HR directors felt might be of interest. Within the public service branches, the sample followed the same format but, due to access issues, focused only at the senior levels.

In all, the sample consisted of 11 women and 24 men (see Table 1) - this involved an oversampling of women managers within both private organisations and a more representative breakdown of the public service branches. The oversampling of women managers occurred as a result of the Executive HR directors suggesting teams that offered good examples of worklife balance and/or teams with unusual working patterns. Furthermore, other differences emerged between the female and male managers; women were much more likely to be at the middle management levels and less likely to have children. This is an important context in which to position the account of the findings below.

Insert Table One about here 
Equally, it is worth noting that these interviews took place in 2008 in Ireland - just before the 2009 recession and property market crash. Over the past two decades, Ireland has also had a unique labour market landscape, first marked by a period of rapid growth where total unemployment dropped from 18 per cent in the late 1980 's to a low of 4.5 per cent in 2007 just prior to this study. The most striking growth in employment levels was women's labour market participation with total employment increasing from 37 per cent in 1993 to 60.5 per cent in 2008 (CSO, 2004, 2008). Culturally, these labour market changes have been linked to major social changes which transformed the experiences of women and men away from traditional household arrangements (Redmond et al. 2006). Organisational case studies were conducted against this cultural backdrop immediately prior to the global recession. Unemployment was less than 5\% and the need to retain employees brought WLB to the fore.

\section{Interviews}

Semi-structured interviews were held with 35 managers between January and May 2008. Prior to each interview, a statement detailing the rationale and background along with confidentiality agreements was provided to all potential participants. All targeted managers agreed to both participate and to have the interviews recorded and transcribed. The interviews spanned 90-120 minutes and were held on-site either in the manager's private office or in a secure room set aside for this purpose.

A broad interview protocol was developed which outlined discussion points and questions in the examination of the role that fairness and gender-role perspectives play in managers' understanding and allocation of work-life balance policies. To this end, some general questions were raised that managers were asked to discuss in the context of their own lives and their organisation. For instance, managers were asked how they would define worklife balance in their own lives with initial responses directed ('can you give an 
example?') and then redirected (\$how does this definition fit with the views of others in your organisation?'). The protocol was designed to lead the conversation through a topic list. In directing the follow up questions, the interviewer attempted to be critically self-aware to ensure that personal views of gender-roles were not reinforced and to allow opportunity for a variety of gender-role beliefs to emerge. One example was asking a manager who mentioned staff working long hours whether this held true for both men and women (traditional genderroles) and asking managers who mentioned mothers using WLB policies whether that extended to fathers or beyond parenting (non-traditional gender-roles). Additionally, there was a vignette that led the managers through a hypothetical workplace scenario.

Managers were also asked about how and when they preferred to support work-life balance arrangements for their staff. Supports spanned a continuum from formal supports (e.g. a reduction in contracted hours or official change in working times) to informal supports (e.g. the manager allows flexitime or time off in lieu). Additionally, a significant portion of the interview was dedicated to discussions of gender-role beliefs. This included more subtle questions that were deliberately scattered throughout the interview schedule aimed at examining views on family structures, parental roles, workers' priorities, and opinions of childcare arrangements as well as a final direct question, at the end of the interview, where each manager was presented with a 5 point visual scale from highly traditional to highly egalitarian and asked to rank their gender-role perspective.

\section{Data Analysis}

A template analysis (King 2004) was employed to analyse themes in the data. An initial version of the template based on the key themes within the literature was devised before the analytic process began. Once the interviews had been transcribed, extracts were coded into broad themes within the template with the help of the software package N-Vivo. 
Further themes were added to the template when data relating to a new theme emerged from the interviews. This revision of coding and themes is typical with this analytic approach where templates can be flexibly structured as a result of emergent and previously unanticipated data (Nadin and Cassell 2004). In order to address the research question, the two over-arching themes in the template were gender-roles and decision-making processes. Each had a number of sub-themes. For example, within 'gender-roles' one sub-theme was 'personal views' which was again sub-divided into lower-order themes; 'views about childcare arrangements' and 'views about partner working patterns'. The 'decision-making process' theme also had a number of sub-themes including 'views about fairness', and 'decisions about the allocation of policies'.

Once the coding was complete, the transcripts were read again in detail and each extract was examined in the context of the transcript to guard against fragmentation. The following findings emerged from careful consideration of the patterns within each of the themes in the template.

\section{Findings}

The findings, illustrating how gender-role beliefs and perceptions of departmental fairness influence managers' work-life balance decisions, are presented in three sections. The first examines the role that organisational justice perspectives play when managers allocate and support work-life balance initiatives; the second examines how perspectives of genderrole beliefs influence decisions; and the third considers how these gender beliefs act in tandem with notions of fairness. Before turning to those sections it is important to point out that the 'life' element of the term work-life balance was overwhelmingly constructed by these managers as associated with, and limited to, the act of supporting caregiving. This was 
primarily seen in terms of parenting with a few cases of elderly care; this is an important context in which to position the account of the findings that follows.

\section{Justice Perspectives}

Managers' notions of fairness emerged as a function of the complexity they attributed to organisational work-life balance programmes and their organisation's position in supporting these arrangements. In illustrating the complex, multi-layered context managers confronted when allocating work-life balance accommodations, managers at all three organisations expressed consistent understanding of respective organisational norms and expectations regarding the allocation of work-life balance arrangements. Across the manufacturing organisation, managers reported having received little direction about how to deal with work-life balance issues but they felt general pressure to keep arrangements to a minimum. The managers at the utility consistently understood — though did not universally agree with — the organisation's ethos of supporting those with caregiving needs while the public service managers went the furthest by suggesting it was their 'duty of care' to accommodate work-life balance needs of their staff.

Unsurprisingly, the level of familiarity with work-life balance policies also related to the manager's position within the organisation. For example, one middle manager of female shift-workers described how managing the operational needs of the business was an ongoing challenge. In contrast, another more senior manager was almost oblivious to how work-life balance could be a divisive issue as it did not seem to impact his completely male team of middle managers. Yet significantly, most managers felt that work-life balance initiatives were often divisive and that part of their management role was to avoid creating resentment within their departments. This was noted particularly by female managers without children who felt that there was too much flexibility and too many arrangements targeted at parents in the workplace leaving those without children ' eeling like we are stuck here holding the can' (female middle manager). Indeed many managers were concerned that the organisational 
ethos was to make arrangements without consideration for the impact on the business particularly for the utility and the public service organisation. Managers at the manufacturing company and those in more senior roles across all three organisations felt that operational considerations affected the decisions they made. This highlights the contradictions around the business case when operational demands conflict with the requirements of work-life balance policies.

Managers also gave a great deal of thought as to how to address a work-life balance issue when it was deemed necessary. The choice of whether to use a formal or informal channel depended upon their views of fairness in the given situation. A senior HR director offered an example of when a manager had a family matter arise and was seeking a formal reduction in hours:

... [I] felt that her contribution over the years have been such that it would have been mean to put her on a formal arrangement where an informal arrangement wasn't going to cost the organisation any money and, from a selfish point of view, I would get it back in spades through loyalty and good will and all that (male senior manager).

The motivation for a manager to grant informal support to one employee while requiring another to rely on more restrictive formal channels can be illuminated through their situational understandings of the request in tandem with their assessment of the petitioner. Managers reported being more likely to support requests when they felt that the individual's organisational commitment merited reward (equity) and/or when the request was for something the manager deemed both significant and worthwhile (need).

To further frame the discussion in the interview, managers were presented with a hypothetical example where they had been asked to allocate a desirable work-life balance benefit within their division that could not be logistically split (such as a laptop for working away from the office). They were asked to discuss how they would confront this task and answers were categorized into the classic distributive justice principles of equality, equity and 
need. In response, over half the managers felt that need was the most appropriate basis of allocating the resource with the remainder split between equity and equality.

The decision about which justice principle to invoke varied greatly between the organisations with managers at the manufacturing organisation more likely to use the equality principle than the public service or utility organisations. Illustrating this, one manufacturing manager claimed that if he could not offer something to everyone on his team then he would not offer it to anyone:

I'd say no, I have to have the same standards. I've had a worker say I'm having a problem at home can I move to days and I have to draw the line there because if I do it for one I won't have anyone working nights (male middle manager).

Even in the event that a particular team member might be experiencing exceptional need, this manager felt that in supporting them, he would be forced to support everyone which he saw as largely impractical. In rejecting the need principle, this manager therefore invoked equality to avoid the appearance of being unfair.

While the preference to allocate based on equality was echoed across this organisation, other managers invoked this principle in slightly different ways. For example, one suggested a lottery approach, "Put the names in a hat — assuming that they're doing the same job at the same level why should one be given priority over the other — try to be as fair as possible" (male senior manager). Alternatively, another suggested setting up a rota: "I would give it to them all together. We'd see if we could rotate it — you do it for 4 weeks - or we would say we can't do it" (male middle manager).

Managers who relied on the equality or equity principle were often defensive of their viewpoint. As one manager pointed out, parents in Ireland already had guaranteed access to statutory leave, so he felt a bit of pressure to be more obliging with requests from non-parents: 
Basically you're saying you give more credence to people who have children ... if you say some groups or some levels are more important than others, you're going to get yourself into bother (male senior manager).

In summary, managers decision-process in adopting one position in relation to fairness rather than another was an active choice and raised difficult issues about the distribution of rewards and support more generally. Managers approached this process from within an understanding that included an active interpretation of the situational context, an assessment of the petitioner, and a larger subjective interpretation of what would constitute fairness in their given situation. This subjective notion of fairness is further illuminated in the following sections which examine perceptions of genderroles and their relationship to views of fairness.

\section{Gender-Role Perceptions}

We now turn to managers' views regarding gender-roles and inherent differences between the sexes. Within our sample, a majority of managers reported perceiving men and women as essentially different. The typical views expressed suggested these differences were most commonly associated with aspects of cultural heteronormative gender-role assumptions around domestic responsibilities in that "woman take the load of the family responsibilities - that's the way that it is, for right or wrong" (a male senior manager). This view was held by both female and male managers: "the male workers do not say I have to go home to collect the kids from school" (female middle manager). Furthermore, these differences were recognised across all organisations in relation to couples who had children. "I believe that females take their domestic life differently, saying 'we work nine to five' and the males work longer hours," (male senior manager).

Managers' views suggest a strong conflation of sex and gender-roles with little separation between perceived biological differences and cultural gender-roles. In fact, while women may have exhibited the most significant workplace adjustments to accommodate 
family life, almost all of the male managers discuss having made adjustments to their working schedules to accommodate their family life, commonly to attend school functions or be home before the children are asleep. Yet these accommodations seemed less salient to managers when discussing gendered working patterns, suggesting hegemonic gender-role assumptions may make the adjustments women make to their working patterns more noticeable.

The conflation of gender and sex was particularly evident when managers at the manufacturing organisation attempted to describe additional differences between men and women in the workplace beyond their familial roles with one noting that "women in a manufacturing environment are always neater and tidier and they always seem to have a calming influence" (male middle manager). Moreover, managers at this same organisation were more likely to discuss women in terms of a greater propensity for being emotional. A few managers mentioned the need to allow women some added space in order to deal with these emotions: "sometimes you need to say, 'why don't you just go get a cup of tea and take a break' - they can get worked up over a problem," (male middle manager). A different manager attributed this to a biological difference between sexes:

We're built differently in that men have an easier life than women in a medical way - in the sense that women have a time of the month. So there is time that their hormones can be off-the-stray. That's an awful thing, you know it cannot be easy for them ... [but] my feeling is that they should be the same every day when really they might be in the straights that day (male middle manager).

From this manager's perspective, such differences are intrinsically linked to deeply ingrained notions of what it means to be a man or a woman.

Views of gender working behaviours varied only slightly by management level and age with senior and older managers slightly more likely to express differences. Yet there did appear to be a strong difference between managers with and without children to the extent that those with children were much more likely to see women and men differently from those 
without. This suggests that managers with children may experience such differences more acutely through their own parenting experience as illustrated by the comments of one manager.

My wife works in an office as well but would be far more conscious on a moment by moment basis of her children, ... I wouldn't feel that I love my children any less than my wife does, but I get into work and I become focused on the work. I really believe it's a male and female thing, with human nature being what it is the women worry about the children more continually. What that means in terms of the question is that female's focus, where there are children involved tend to be split a little. It doesn't, in my experience, diminish the quality of the work, but it can diminish the focus or concentration, typically, when women work they have to work harder to focus. (male middle manager)

Conversely, when managers themselves had not experienced parenthood, true of both male and female managers, they are less likely to formulate these perceptions of difference; "It's not something I would consider, people are people, because they're a woman or a man makes absolutely no difference" (middle manager male).

When discussing gender working behaviours, many managers pointed to the changing economic environment in Ireland over the preceding decade that had encouraged more mothers into the labour market. Managers, particularly at senior levels, felt that despite this increase there were inherent differences between men and women's priorities - in that women saw their role in the workplace as secondary to their role in the family. Many managers referred to this with biological essentialist terms like 'maternal instinct' and the way 'nature intended'.

In illustrating the power and influence of this perspective, one HR senior manager at the manufacturing firm suggested that the problem with non-traditional working options is they cannot overcome the inherent desire in women to mother. To support this he cited an example of a new mother he was unable to entice back to work after the birth of her child. He pointed to this example as a reason the organisation did not have any work-life balance policies, he felt that 'women's maternal instincts are ferocious and nothing can overcome 
that' (male senior manager). This perspective was echoed by male managers across the manufacturing and utility company - particularly strong for those in senior roles. For the most part, the public service managers and female managers at all organisations alongside a few of the male middle managers did not share this view. Yet the senior managers who did, illustrate how personal understandings can narrow how they view work-life balance policies - as a deficient response to the economic need of women to work. Accordingly, despite shifts to gender-neutral terms, most of the managers illustrate an interpretation that is deeply rooted in gender-role differences.

There were also some interesting findings in terms of managers self-labelling gender-role perspectives with the results suggesting that how these managers label themselves does not necessarily lead to a predictable set of assumptions about their attitudes and behaviours. Indeed, there was a high degree of inconsistency in many of the self-labelled gender-role beliefs and the gender-role attitudes and behaviours expressed throughout the interviews. Perhaps unsurprising, given the current emphasis on gender equality, most managers categorised themselves on the highly egalitarian side of genderrole beliefs while only a few identified as being highly traditional. However, out of the managers who classified themselves as highly egalitarian, many appeared to hold divergent attitudes and characteristics in expressing more traditional viewpoints - a finding that was particularly salient in older male managers.

One male senior manager illustrates this 'fracture' by describing himself as highly egalitarian yet, when discussing work-life balance, his responses and life choices reflected a more traditional viewpoint. For example in discussing childcare arrangements he said he was happy that his wife was "able to stay at home" when his children were young and felt that "the quality of life is really hurt when women have to work". These statements conflict with what one would expect from a self-definition as highly egalitarian. Indeed, he went on to 
argue "that the old fashioned way, when you can afford it, is the best," suggesting a view that egalitarian life choices are something forced on families who are not in the financial position to afford the "traditional way".

In another example, a male middle manager who self-identified as egalitarian argued he would put the rest of his life's earnings on the fact that human nature kept women from achieving higher management levels in his organisation. He felt that:

Women's energy and focus and concentration and intuition was aimed at children and this is incompatible with higher management which really demands your time, it demands your full concentration and that is not a condition that even the most career driven of women can live with if they have children.

Similar findings held true for men across organisations and management levels with the exception of managers without children and female managers who were less likely to exhibit this fracture. While these findings demonstrate how gender-role beliefs play a vital role in managers' understanding of work-life balance programmes, they also illustrate the risk of gender-role fracture and the problematic assumption around self-labelled beliefs and predictable assumptions around work-life balance.

\section{Linking gender and justice perspectives}

Perhaps the most striking finding in the data occurred when perceptions of genderroles were evaluated in conjunction with managers' decision-making process. Alongside an awareness of the general organisational ethos towards work-life balance, managers at both organisations reported having a large degree of discretion about whether to offer formal or informal arrangements. Patterns emerged from the data as follows; It became evident that managers' decisions are not only narrowed by the socially-embedded organisational context in which they operate (for example, a highly tuned awareness of the views of their direct senior managers) but also by the interplay between their personal understandings of gender- 
roles and fairness. In analysing this process, managers' personal beliefs regarding gender-roles and their perception of inherent differences between men and women influenced which justice principle they used to create the fairest distribution of work-life balance programmes and their preferred channel of allocation (formal or informal). Managers who espoused more traditional views of gender-role were more inclined to allocate programmes on an informal basis compared with managers holding more egalitarian views of gender-roles. In exploring this phenomenon, there were two relevant findings: first, managers used informal channels to reward behaviour and loyalty; and second, formal channels were considered more transparent and only used when there were no concerns about setting precedence.

These differences were further illuminated by examining the managers' understandings of inherent differences between the sexes and how this influenced their decisions regarding whether need, equality or equity was the fairest way to allocate supports. Managers who reported not seeing any inherent differences between men and women preferred to invoke the 'need' principle. In contrast, the 'equality' or 'equity' principles were preferred by managers who saw a gendered distinction. Accounting for this disparity, managers who saw a difference often expressed it in terms that conflated sex and gender-role differences which they associated with women's greater share of domestic responsibilities as a workplace 'spill-over' that, they argued, resulted in a greater need for workplace supports for women. Accordingly, these managers reasoned that by allocating supports in terms of need they were inherently fostering workplace inequality. As one senior manager pointed out, despite the recognisable 'need' differences for parents, there was a tertiary aspect of work-life balance issues in finding ways to avoid being seen as discriminatory:

You get into issues then, maybe people trying to have kids and can't, they get this thing in the back of their heads, there's an opportunity to have a nicer life at work and it doesn't happen because I don't have kids (male senior manager). 
Moreover, managers who felt that there was a gender difference were more likely to invoke a principle they felt would alleviate this intrinsic 'weakness' in the need principle. By allocating desirable supports as either a reward for workplace performance (equity) or on a transparent equality basis (first-come / all-or-nothing) they hoped to avoid backlash. Yet managers who felt that men and women were the same would see women as having no inherently greater 'need' of supports resulting in the 'need' principle being applied equally.

This interplay between gender and justice is further evident when we examine which distribution principle the managers' preferred. Similarly to above, those who spoke about gender-roles in more 'traditional' terms were less likely to invoke the 'need' principle when deciding how to allocate initiatives, whilst almost all of the managers who espoused more 'egalitarian' gender-roles beliefs, such as suggesting that parents should take equal responsibility for children, used 'need' as a basis for allocation. Similarly, the managers who held more traditional views of gender-roles tended to see women's position in the workplace as secondary to their domestic roles. Accordingly, these managers expressed concern that many of these programmes appeared to create an unfair work distribution for those dealing with departmental absences. As a result, rather than such policies minimising gender inequality in the workplace, these managers viewed them as a vehicle for creating inequality in the form of men being on the receiving end of an increased workload. Conversely, managers who believed that fathers and mothers held equal responsibility for childcare saw these workplace arrangements not as 'extra' benefits but as necessary to support the individuals and offer families the flexibilities they needed. Accordingly, managers' view of justice in these situations was contingent on their personal understandings of gender-role behaviours.

The influence and power of these views is evident when returning to the organisational context in which they operate. Managers across all organisations 
acknowledged organisational and legislative pressure to respond positively to certain requests but also highlighted their own power to allocate such supports formally or informally. In this regard, managers with more traditional views of gender-roles preferred 'equality' and 'equity' principles and felt that certain work-life balance programmes were unfair to those who do not have 'equal' need of such support. Correspondingly, when these managers were faced with organisational or legislative pressure to provide these supports they could use their power to reduce departmental inequality through the use of formal or informal channels; saving informal channels as a way to reward individual commitment and drawing on a more difficult formal process for those they felt had an unfair advantage.

On the other hand, managers who held more egalitarian views saw the process quite differently; they suggested that those in need of a support should be offered a formal delivery system because that would represent the most transparent and fair distribution method. When considering this finding, it is important to note that none of the managers with traditional views on gender roles had partners working full-time yet all of the more egalitarian managers had partners who worked, mostly on a full-time basis. Consequently, these managers spoke of their own shared domestic responsibility referring to dividing out school runs and childcare as well as weekends spent seeing to household chores. Based on the added pressure of domestic responsibilities, these managers were less flexible in relation to working hours than their peers who enjoyed the support of a stay-at-home partner and were, subsequently, the least likely to benefit through the reward-based 'equity' principle while conversely being the most likely to qualify on the basis of 'need'.

In summary, these managers' understandings of work-life balance needs and their sense of how to fairly allocate supports are embedded in their underlying understandings of gender-roles and inherent differences between men and women. The operation of work-life balance programmes depend fundamentally upon managerial interpretation. In other words, 
managers process decisions through an active interpretation of their organisational context which is informed by gender-role assumptions, all of which serve to narrow their available options in determining how to allocate work-life balance arrangements fairly.

\section{Discussion: Management perceptions of gender, fairness and justice}

Our findings highlight the role of managers and managerial discretion in the uptake of work-life balance policies and provide further evidence of the significance of line managers in human resource functions (Currie and Procter 2001; Brandl et al. 2009; Den Dulk et al. 2011). In focusing upon the link between personal perspectives and views of work-life balance using qualitative methods, we were able to demonstrate how managers' views of gender-roles are closely linked with their understandings of fairness in the allocation of work-life balance programmes. Despite recent attempts to shift work-life balance discourse along gender-neutral lines, these managers confirmed previous findings (Smithson and Stokoe 200 5) by demonstrating an understanding and approach to work-life balance policies as support for the care-giving needs of working mothers. Our findings therefore illustrate and further extend understandings that work-life balance is understood as a response to heteronormative constructions of the family and the problems created in managing work and family demands in the workplace (Ozbiglin et al. 2011; Gatrell et al. 2013).

The construction of work-life balance in this way has interesting implications for equality in the workplace. As long as the 'life' part of work-life balance continues to be understood by managers in this way these policies will serve to reinforce traditional genderroles and strengthen discrimination. This occurs not only by normalising and privileging the idea of 'male breadwinner' but does so hidden beneath claims of gender-neutrality. Furthermore constructions of work-life balance are being played out in organisational contexts that both construct and reflect gendered assumptions (Green and Cassell, 1996). 
Although final decisions were affected by personal views, the managers here - similar to those in Reeve et al's (2012) study - were influenced by cultural pressures. These heteronormative constructions of the "life" part of work-life balance are significant in that the managerial understandings both reflect and help to sustain the gendered assumptions that underpin organisational cultures.

The implications are important for work-life balance researchers. Examinations of managerial influence on work life balance need to be coupled with a powerful and nuanced understanding of how heteronormative constructions affect the decision-making process and constrain the use of policies. Without a clear understanding of how these elements play out in a day-to-day context, research risks misinterpreting the influence of other issues at play.

There are a number of other findings. First, one which does not appear to have been addressed previously, is that when managers are confronted with difficult choices over the allocation of finite resources, they seek reconciliation through the formal-informal continuum. In this manner, even where managers feel socially or institutionally obliged to allow access to supports, they can nevertheless recover a degree of influence by deciding whether to meet these supports informally or through formal channels. Similarly, when managers feel legally obligated to offer supports, such as statutory leave, they often still enjoy a degree of influence in restricting how leave can be taken (e.g. continuously or spread out over time). In this manner, they retain the power to enact their views of justice and gender-roles despite legal or organisational obligations. The disruption and dependency considerations highlighted by Den Dulk et al (2008) also influence manager's priorities. Managing the tensions of a variety of business cases is an additional tension here. Offering WLB supports can be problematic when faced with operational demands. This finding regarding the formality / informality continuum highlights a potentially promising avenue for future research into managerial discretion that could be progressed to more fully expand 
previous work on this phenomenon (Anderson et al. 2002; Behson 200 5). Specifically, by recognizing this avenue for the manifestation of managerial decision-making, research can develop a more nuanced understanding of the decision-making process. While managers may be able to say they supported a certain WLB request, by explicating the detail behind the process, we can ascertain a larger understanding of how personal perspectives can still constrain the use of policy.

A second contribution highlights and explicates in detail the factors that influence managerial decision-making processes. In so doing, we have raised the issue of inconsistency between self-labelled gender-role beliefs and individual behaviour. Specifically, drawing on previous research (Hochschild 1989), we found a disconnect whereby managers would selfidentify as gender egalitarian while their life decisions and personal views pointed to more traditional approaches. The identification of this 'fracture' in the context of work life balance research is important both theoretically and methodologically. Theoretically we are reminded to be careful not to assume that a particular set of beliefs will lead to corresponding assumptions about behaviour. Accordingly, while previously literature has attempted to link specific views of gender-role beliefs to the resentment of policies (e.g. Grover 1991; Hegtvedt et al. 2002), our findings imply that this inconsistency may play a complicating role. Methodologically, given that gender-roles beliefs are active on a more complex level than can be captured by simple self-description labels or even basic questions about gender-role equality, it is important that researchers approach data collection with strategies that anticipate inconsistency and reach beyond self-labelled gender-role beliefs. Our qualitative approach has been useful in illuminating these inconsistencies. It is important to note here that we are not being judgemental about these inconsistencies. Rather, as has increasingly been recognised, contradictory stances are fairly common in organisational life (see ElSawad, Arnold and Cohen, 2004). Raising awareness of this, we suggest that work life 
balance topics are so deeply embedded with 'fractured' issues of gender-role beliefs that it is important that researchers take an approach that anticipates this inconsistency.

There are some contextual issues that are worth drawing attention to here. Our findings suggest that the allocation of work-life balance supports is a contested domain influenced by gender-role beliefs, perceptions of justice and other operational and cultural demands that managers face. However, it is important to point out that the economic context in which the research is conducted is also significant. At time of writing the economic context in Ireland is very different from that when the research was conducted with the recession having an impact upon all areas of the public and private sectors. Accordingly, access to work-life balance can be affected by a range of other issues that managers have to deal with such as rising unemployment and lack of occupational mobility. This will add another layer to the multi-layered approach that is needed to fully understand manager's decisions to award access to such policies.

Finally, and most significantly, we have extended the link between gender-role beliefs and organisational justice theory to issues of work-life balance and considered how this works in practice. Research examining perspectives of justice in the division of household labour has widely noted a link between gender-role beliefs and perspectives of fairness (Blair and Johnson 1992; Ruppanner 2008; Kawamura and Brown 2010). Here we build upon these findings to extend and expand them into the area of organisational work-life balance decision-making by further confirming the importance of personal managerial perspectives to organisational allocation and dissemination processes (den Dulk and de Ruijter 2008; Poelmans and Beham 2008; McCarthy et al. 2010).

In terms of organisational justice theory and the subjective notion of fairness, our findings show how gender-role beliefs can illuminate how managers approach work-life balance decisions and specifically which of the organisational justice principles managers 
employ in a given situation as well as the degree of formality to be engaged in the arrangement. Using this gender-role/justice interplay might provide an alternative explanation for why some individuals in previous studies did not report resentment to policies they themselves were unable to use (Grover 1991; Young 1999; Bernerth et al. 2011) in that this inequality was legitimised and mitigated by their personal gender-role beliefs (Braun et al. 2008). For example, within our sample, managers with children were the most likely to discuss men and women in essentialist terms and report that work-life balance supports inherently foster workplace inequality while those without children instead suggest that all workers have equal need of work-life balance supports and therefore they are not inherently unjust. This finding contradicts reports that employees without children are the most likely to report injustice in their inability to access these programmes (Young 1999; Teasdale 2013). We argue that the report of injustice is a more complex process than has been previously captured and is influenced by personal context, such as gender-role beliefs, ideas of fairness, and parenting experience. These in turn directly influence individual understandings and approaches to work-life balance supports. Similarly, we provide evidence that wider research into organisational justice would benefit from a stronger acknowledgement of subjective notions of fairness and consideration of gender-role theory (Cropanzano et al. 2007; Bernerth et al. 2011; Fuchs and Edwards 2012).

\section{Conclusions}

In making sense of the interrelationships between gender-role beliefs, distributive justice, and the decision-making process of work-life balance policies we contend that subjective notions of fairness and beliefs of gender-roles form what can be viewed as an integrated gender-role/justice framework where notions of fairness act in tandem with personal beliefs in guiding a manager's understandings of organisational work-life balance 
policies and practices. In other words, where managers may be more consciously aware of their notions of fairness in allocating supports, these notions are themselves subject to and filtered through largely hidden beliefs about gender-roles in the workplace. In turn these need to be understood within the confines of organisational cultures and the extensive and increasing demands placed on managers in the contemporary workplace (Ford and Collinson, 2011), including managing a variety of business cases.

In summary, we have highlighted the heteronormative understandings of work-life balance held by managers and have illuminated how managerial perspectives of gender-roles temper the decision process around work-life balance allocation even when they may not appear to be relevant. Given the complex nature of decision-making processes we argue that the identification of such phenomena requires a shift in our approach to work-life balance research from a focus on policy to a focus on the complexity of managers' decision-making processes. As this research has illustrated, it is the 'human' elements in this process that are perhaps more influential than the formal policies in place. The practical implications of refocusing on managers' constructions of work-life balance and their influence on allocations will allow researchers a greater chance of understanding the complexities surrounding these issues in their pursuit of stronger policy and organisational recommendations. 


\section{REFERENCES}

Adams, J. S. (196 5). Inequity in social exchange. Advances in experimental social psychology. L. Berkowitz. New York, Academic Press.

Allen, D. G., L. M. Shore and R. W. Griffeth (2003). "The role of perceived organisational support and supportive human resource practices in the turnover process." Journal of Management 29(1): 99-118.

Allen, T. D. (2001). Family-supportive work environments: The role of organisational perceptions. Conference of the Academy-of-Management, Chicago, Illinois.

Anderson, S. E., B. S. Coffey and R. T. Byerly (2002). "Formal organisational initiatives and informal workplace practices: Links to work-family conflict and job-related outcomes." Journal of Management 28(6): 787-810.

Appelbaum, E. and L. Golden (2002). The standard workday or the highway. Washington, DC, Center for the Designing Work Wisely.

Beauregard, A. (2014). "Fairness Perceptions of Work-Life Balance Initaitive: Effects on Counterproductive Work Behaviour." British Journal of Management 2 5: 772 - 789.

Behson, S. (200 5). "The relative contribution of formal and informal organisational work-family support." Journal of Vocational Behavior 66: 487- 500.

Berk, S. (198 5). The gender factory. New York, Plenum.

Bernas, K. H. and D. A. Major (2000). "Contributors to stress resistance - Testing a model of women's work-family conflict." Psychology of Women Quarterly 24(2): 170-178.

Bernerth, J. B., H. J. Walker, F. Walter and R. R. Hirschfeld (2011). "A Study of Workplace Justice Differences During Times of Change: It's Not All About Me." Journal of Applied Behavioral Science 47(3): 336-3 59.

Blair, S. and M. Johnson (1992). "Wives' Perception of Fairness and the division of household labor." Journal of Marriage and the Family 54: 570- 581.

Bond, J., E. Galinsky and J. E. Swanberg (1998). The 1997 National Study of Changing Workforce. New York, Families and Work Institute.

Brandl, J., M. T. Madsen and H. Madsen (2009). "The perceived importance of HR duties to Danish line managers." Human Resource Management Journal 19(2): 194-210.

Braun, M., N. Lewin-Epstein, H. Stier and M. K. Baumgartner (2008). "Perceived Equity in the Gendered Division of Household Labor." Journal of Marriage and Family 70( 5): 114 5- 1156.

Byrne, Z. and R. Cropanzano (2001). History of organisational justice: The Founders Speak. Justice in the workplace. R. Cropanzano. Mahwah, NJ, Lawrence Erlbaum: p. 3-26. Casper, W. J., K. E. Fox, T. M. Sitzmann and A. L. Landy (2004). "Supervisor referrals to workfamily programs." Journal of Occupational Health Psychology 9(2): 136-1 51. Chang, A., P. McDonald and P. Burton (2010). "Methodological choices in work-life balance research 1987 to 2006: a critical review." International Journal of Human Resource Management 21(13): 2381-2413.

Crompton, R., M. Brockmann and C. Lyonette (200 5). "Attitudes, women's employment and the domestic division of labour: a cross-national analysis in two waves." Work Employment and Society 19(2): 213-233.

Crompton, R. and Lyonnete, C. (2006). The new gender essentialism - domestic and family 'choices' and their relation to attitudes. British Journal of Sociology, 56, 601-620 Cropanzano, R., D. E. Bowen and S. W. Gilliland (2007). "The management of organisational justice." Academy of Management Perspectives 21(4): 34-48. Currie, G. and S. Procter (2001). "Exploring the relationship between HR and middle managers." Human Resource Management Journal 11(3): 53-69. 
De Cieri, H, Holmes, B., Abbott, J. and Pettit, T. (200 5). Achievements and challenges for work/life balance strategies in Australian organizations. International Journal of Human resource Management Volume 16, issue 1, pages 90-103.

Den Dulk, L. and J. de Ruijter (2008). "Managing work-life policies: disruption versus dependency arguments. Explaining managerial attitudes towards employee utilization of work-life policies." International Journal of Human Resource Management 19(7): 1222-1236. Den Dulk, L., B. Peper, N. C. Sadar, S. Lewis, J. Smithson and A. Van Doorne-Huiskes (2011). "Work, Family, and Managerial Attitudes and Practices in the European Workplace: Comparing Dutch, British, and Slovenian Financial Sector Managers." Social Politics 18(2): 300-329.

Deutsch, M. (197 5). "Equity, Equality, and Need - What Determines Which Value Will Be Used as Basis of Distributive Justice." Journal of Social Issues 31(3): 137-149. El-Sawad, A., Arnold, J., and Coihen, C. (2004). 'Doublethink': the prevalence and function of contradiction in accounts of organizational life. Human Relations, 57(9): 1179-1203. Emslie, C. and Hunt, K. (2009). 'Live to work' or 'work to live'? A qualitative study of gender and work-life balance among men and women in mid-life. Gender, Work and Organization, 16, 1 51-172.

Folger, R. and M. A. Konovsky (1989). "Effects of Procedural and Distributive Justice on Reactions to Pay Raise Decisions." Academy of Management Journal 32(1): 11 5-130. Ford, J. and Collinson, D. (2011). In search of the perfect manager: work life balance and managerial work. Work, Employment and Society, 25, 257-273.

Frone, M. R., M. Russell and M. L. Cooper (1992). "Antecedents and outcomes of work family conflict - testing a model of the work family interface." Journal of Applied Psychology 77(1): 6 5-78.

Frye, N. K. and J. A. Breaugh (2004). "Family-friendly policies, supervisor support, workfamily conflict, family-work conflict, and satisfaction: A test of a conceptual model." Journal of Business and Psychology 19(2): 197-220.

Fuchs, S. and M. R. Edwards (2012). "Predicting pro-change behaviour: the role of perceived organisational justice and organisational identification." Human Resource Management Journal 22(1): 39- 59.

Gatrell, C.J., Burnett, S.B., Cooper, C.L. and Sparrow, P. (2013) Work-life balance and parenthood: a comparative review of definitions, equity and enrichment.

International Journal of Management Reviews, 15, 300-316.

Grandey, A. (2001). Family friendly policies: Organisational Justice perceptions of needbased allocations. Justice in the Workplace. R. Cropanzano. Mahwah, $\mathrm{Nj}$, Lawrence Erlbaum: p 14 5-173.

Grandey, A., \& Cordeiron, B. (2002). Family-friendly policies and organizational justice. Resources for Teaching: Work and Family Encyclopedialn E. Kossek \& M. Pitt-Catsouphes (Eds.), Work and family encyclopedia. Chestnut Hill, MA: Sloan Work and Family Research Network. Retrieved October 16, 2013, from https://workfamily.sas.upenn.edu/wfrnrepo/object/74y9ov50xr2yw0p6

Green, E. and Cassell, C.M. (1996). Women managers, gendered cultural processes and organisational change. Gender, Work and Organisation, 3 (3) : 168-178.

Greenhaus, J. and Beutell, N. (198 5). Sources of conflict between work and family roles. Academy of Management Review, 10, 72-79.

Greenstein, T. N. (1996)a. "Gender ideology and perceptions of the fairness of the division of household labor: Effects on marital quality." Social Forces 74(3): 1029-1042.

Greenstein, T. N. (1996)b. "Husbands' participation in domestic labor: Interactive effects of wives' and husbands' gender ideologies." Journal of Marriage and the Family 58(3): 58 5- 595. 
Gregory, A. and Milner, S. (2009). Work-life balance: a matter of choice? Gender, Work and Organization, 16, 1-3.Grover, S. L. (1991). "Predicting the Perceived Fairness of Parental Leave Policies." Journal of Applied Psychology 76(2): 247-2 55.

Grover, S. L. (1991). "Predicting the perceived fairness of parental leave policies." Grzywacz, J. G., \& Marks, N. F. (2000). Family, work, work-family spillover and problem drinking during midlife. Journal of Marriage and the Family, 62(2), 336-348. Hegtvedt, K. A., J. Clay-Warner and E. D. Ferrigno (2002). "Reactions to injustice: Factors affecting workers' resentment toward family-friendly policies." Social Psychology Quarterly 65(4): 386-400.

Hegtvedt, K. A. and C. Killian (1999). "Fairness and Emotions: Reactions to the Process and Outcomes of Negotiations." Socal Forces(78): 269-302.

Hochschild, A. (1989). The Second Shift. New York, Viking.

Homans, G. (1974). Social Behaviour: Its Elementary Forms. New York, Harcourt, Brace and World.

Howard, J. and J. Hollander (1997). Gendered Situations, Gendered Selves. Thousand Oaks, CA, Sage.

Jespen, D. and J. Rodwell (2010). "Female Perceptions of Organisational Jusitce." Gender, Work and Organisation: doi: 10.1111/j.1468-0432.2010.00 538.x.

Kawamura, S. and S. Brown (2010). "Mattering and wives' perceived fairness of the division of household labor." Social Science Research 39: 976-986.

King, N. (2004). Using templates in the thematic analysis of texts. Essential guide to qualitative methods in organisational research. C. Cassell and G. Symon. London, Sage.

Kossek, E. E., S. Lewis and L. B. Hammer (2010). "Work-life initiatives and organisational change: Overcoming mixed messages to move from the margin to the mainstream." Human Relations 63(1): 3-19.

Kroska, A. (1997). "The division of labor in the home: A review and reconceptualization." Social Psychology Quarterly 60(4): 304-322.

Lapierre, L. M., P. E. Spector, T. D. Allen, S. Poelmans, C. L. Cooper, M. P. O'Driscoll, J. I. Sanchez, P. Brough and U. Kinnunen (2008). "Family-supportive organisation perceptions, multiple dimensions of work-family conflict, and employee satisfaction: A test of model across five samples." Journal of Vocational Behavior 73(1): 92-106.

Lewis, J. and M. Campbell (2007). "UK work/family balance policies and gender equality, 1997-200 5." Social Politics 14(1): 4-30.

Lewis, J. and M. Campbell (2008). "What's in a name? 'Work and family' or 'work and life' balance policies in the UK since 1997 and the implications for the pursuit of gender equality." Social Policy \& Administration 42( 5): 524- 541.

McCarthy, A., C. Darcy and G. Grady (2010). "Work-life balance policy and practice: Understanding line manager attitudes and behaviors." Human Resource Management Review 20(2): 1 58-167.

McDonald, P., B. Pini and L. Bradley (2007). "Freedom or fallout in local government? How work-life culture impacts employees using flexible work practices." International Journal of Human Resource Management 18(4): 602-622. McGuire, D., T. Garavan, S. Saha and D. O'Donnell (2006). "The impact of individual values on human resourse decicion-making by line managers." international Journal of Manpower 27(3): 2 51-273.

Nadin, S. and C. Cassell (2004). Using data matrices. Essential guide to qualitative methods in organisational research. C. Cassell and G. Symon. London, Sage.

Nomaguchi, K. M., M. A. Milkie and S. M. Bianchi (200 5). "Time strains and psychological well-being: Do dual-earner mothers and fathers differ?" Journal of Family Issues 26(6): 7 56792. 
Ozbiglin, M.F., Beauregard, A., Tatli, A and Bell, M.P. (2011). Work-life, diversity and intersectionality: a critical review and research agenda. International Journal ofManagement Reviews, 13, 177-198.

Parasuraman, S. and J. H. Greenhaus (2002). "Toward reducing some critical gaps in work-family research." Human Resource Management 12: 299-312.

Poelmans, S. and B. Beham (2008). "The moment of truth: Conceptualizing managerial work-life policy allowance decisions." Journal of Occupational and Organisational Psychology 81: 393-410.

Reeve, B.H., Broom, D.H., Strazdins, L. And Shipley, M. (2012). Regulation, managerial discretion and family-friendliness in Australia's changing industrial relations climate. Journal of Industrial Relations, 54 (1): 57-74.

Reiter, N. (2007). "Work Life Balance: What DO You Mean ?: The Ethical Ideology Underpinning Appropriate Application." The Journal of Applied Behaviorial Science 43(2): 273-294.

Ruppanner, L. (2008). "Fairness and Housework: A Cross-National Comparison." Journal of Comparative Family Studies 39(4): 509-+.

Russell, H., P. J. O'Connell and F. McGinnity (2009). "The Impact of Flexible Working -97. Arrangements on Work-life Conflict and Work Pressure in Ireland." Gender Work and Organisation 16(1): 73

Schwinger, T. (1986). The need principle of distributive justice. Justice in Social Relations. H. W. Bierhoff, R. L. Cohen and J. Greenberg. New York, Plenum.

Skarlicki, D. P. and R. Folger (1997). "Retaliation in the workplace: The roles of distributive, procedural, and interactional justice." Journal of Applied Psychology 82(3): 434443. Smithson, J. and E. H. Stokoe (200 5). "Discourses of work-life balance: Negotiating 'genderblind' terms in organisations." Gender Work and Organisation 12(2): 147-168.

Swanberg, J. E., M. Pitt-Catsouphes and K. Drescher-Burke (200 5). "A question of justice Disparities in employees' access to flexible schedule arrangements." Journal of Family Issues 26(6): 866-89 5.

Teasdale, N. (2013). "Fragmented Sisters? The Implications of Flexible Working Policies for Professional Women's Workplace Relationships." Gender, Work \& Organisation 20(4): 397- 412.

Theodorakapoulos, N. and Budhwar, P. (201 5) Diversity and Inclusion in Different Work Settings: Emerging Patterns, Challenges, and Research Agenda. Human Resource Management volume 54, issue 2, pages 117-197.

Thompson, C. A., L. L. Beauvais and K. S. Lyness (1999). "When work-family benefits are not enough: The influence of work-family culture on benefit utilization, organisational attachment, and work-family conflict." Journal of Vocational Behavior 54(3): 392-41 5. Todd, P. and Binns, J. (2013) "Work-Life Balance: Is it Now a Problem for Management?" Gender, Work and Organization 20(3): 219-231.

Warren, J. A. and P. J. Johnson (199 5). "The impact of workplace support on work family role strain." Family Relations 44(2): 163-169.

Warren, T. (2004). "Working part-time: achieving a successful 'work-life' balance?" British Journal of Sociology 55(1): 99-122.

West, C., \& Zimmerman, D. H. (1987). Doing gender. Gender \& Society, 1(2), 12 5-1 51 Young, M. B. (1999). "Work-family backlash: Begging the question, what's fair?" Annals of the American Academy of Political and Social Science 562: 32-46. 
Table 1 Breakdown of participants

\begin{tabular}{|l|c|c|c|c|c|c|}
\hline & \multicolumn{2}{|c|}{ Manufacturing } & \multicolumn{2}{c|}{ Utility } & $\begin{array}{c}\text { Public } \\
\text { Service }\end{array}$ & \\
\hline & Middle & Senior & Middle & Senior & Senior & Total \\
\hline Male & 10 & 3 & 4 & 4 & 3 & 24 \\
\hline Female & 2 & & 7 & & 2 & 11 \\
\hline Total & 12 & 3 & 11 & 4 & 5 & 35 \\
\hline
\end{tabular}

